\title{
Sistem Pakar Online Pendeteksi Penyakit Tanaman Adenium Dengan Metode Prototyping
}

\author{
Syahriani ${ }^{1}$, Dimas Aryo Dirgantoro² \\ ${ }^{1}$ STMIK Nusa Mandiri Jakarta \\ e-mail: azhura.sensei@gmail.com \\ STMIK Nusa Mandiri Jakarta \\ email: dimasaryodirgantoro@gmail.com
}

Cara Sitasi: Syahriani , S., \& Dirgantoro, D. A. (2019). Sistem Pakar Online Pendeteksi Penyakit Tanaman Adenium Dengan Metode Prototyping. Jurnal Teknik Komputer, 51-58. doi:10.31294/jtk.v5i1.4287

\begin{abstract}
This adenium plant is a plant that began to demand by many hobbyist plants because plants have unique characteristics Adenium. In addition adenium treatment is also very easy, but adenium plants are also susceptible to pest disease, so it becomes a disease that can make this adenium plant damaged or dead. The lack of expert on adenium plant diseases causes the hobbyists to find it difficult to recognize the symptoms and ways to cure when the plant is infected with the disease. This expert system is made to facilitate the hobbyists in coping with adenium plant diseases. The method used in this expert system is forward chaining, because the Forward Chaining method is a suitable method for the control and forecasting of adenium plant diseases. This expert system application will display the question about the symptoms of adenium plant disease that attack and can be found the solution by experts who have experienced in their field, after that the system will display the results of the disease that attacks his adenium plants along with the characteristics and how to cope with the disease.
\end{abstract}

Keywords: Adenium, Expert System, Forward Chaining

\section{PENDAHULUAN}

Menurut Giarratano dan reley dalam Merlina dan Rahmat (Merlina, 2012). Sistem pakar adalah suatu sistem komputer yang bisa menyamai atau meniru kemampuan seorang pakar. Pakar yang dimaksud di sini adalah orang yang mempunyai keahlian khusus yang dapat menyelesaikan masalah yang tidak dapat diselesaikan oleh orang awam (Kusrini, 2008). Sistem pakar diharapkan dapat menghasilkan dugaan atau hasil diagnosa yang sama dengan diagnosa yang dilakukan oleh seorang ahli .

Sistem pakar memiliki beberapa metode, salah satunya metode Inferensi. Inferensi merupakan proses untuk menghasilkan informasi dari fakta yang diketahui atau diasumsikan. Inferensi adalah konklusi logis (logical conclusion) atau implikasi berdasarkan informasi yang tersedia. Dalam sistem pakar proses inferensi dilakukan dalam suatu modul yang disebut Inferece Engine (Mesin inferensi). Ada dua metode inferensi yang penting dalam sistem pakar yaitu: runut maju (forward chaining) dan runut balik (backward chaining) (Kusrini, 2008).

Menurut Giarratano dan reley dalam Merlina dan Rahmat (Merlina, 2012). Sistem pakar adalah suatu sistem komputer yang bisa menyamai atau meniru kemampuan seorang pakar. Pakar yang dimaksud di sini adalah orang yang mempunyai keahlian khusus yang dapat menyelesaikan masalah yang tidak dapat diselesaikan oleh orang awam (Kusrini, 2008). Sistem pakar diharapkan dapat menghasilkan dugaan atau hasil diagnosa yang sama dengan diagnosa yang dilakukan oleh seorang ahli .

Sistem pakar memiliki beberapa metode, salah satunya metode Inferensi. Inferensi merupakan proses untuk menghasilkan informasi dari fakta yang diketahui atau diasumsikan. Inferensi adalah konklusi logis (logical conclusion) atau implikasi berdasarkan informasi yang tersedia. Dalam sistem pakar proses inferensi dilakukan dalam suatu modul yang disebut Inferece Engine (Mesin inferensi). Ada dua metode inferensi yang penting dalam sistem pakar yaitu: runut maju (forward chaining) dan runut balik (backward chaining) (Kusrini, 2008).

\section{METODOLOGI PENELITIAN}

\section{Runut Maju (Forward Chaining)}

Menurut Wilson dalam kusrini (Kusrini, 2008) "runut maju berarti menggunakan himpunan aturan kondisiaksi. Dalam metode ini, data digunakan untuk menentukan aturan mana yang akan dijalankan, 
kemudian aturan tersebut dijalankan. Mungkin proses menambahkan data ke memori kerja. Proses diulang sampai ditemukan suatu hasil". Metode inferensi runut maju cocok digunakan untuk menangani masalah pengendalian (controlling) dan peramalan (prognosis).

\section{Model Pengembangan}

Adapun tahapan-tahapan dalam model protoype ini adalah sebagai berikut:

\section{A. Analisa Kebutuhan}

Pada tahap ini dilakukan pengumpulan data yang diperlukan seperti mengumpulkan data gejala-gejala, klarifikasi penyakit, aturan-aturan diagnosa pada tanaman adenium, serta kumpulan informasi seputar tanaman adenium guna menentukan spesifikasi dan konten perangkat lunak sistem pakar yang akan dirancang. Aplikasi website ini dibuat hanya untuk administrator system dan pengunjung.

\section{B. Pembuatan Prototyping}

Setelah mengetahui seluruh kebutuhan yang diperlukan, tahap selanjutnya adalah membangun protoyping dengan membuat perancangan sementara yang berfokus pada penyajian kepada pengguna (rancangan form input dan output sementara).

\section{Evaluasi Prototyping}

Langkah selanjutnya adalah melakukan evaluasi dengan mendatangi pihak client untuk melakukan pengecekan apakah prototyping yang dibangun sudah layak dan sesuai dengan keinginan client.

D. Coding System

Dalam pembuatan prototyping aplikasi website ini, menggunakan berbagai macam bahasa pemrograman yaitu HTML, CSS, PHP.

\section{E. Pengujian Sistem}

Sistem yang sudah jadi dan siap dipakai ini, harus dilakukan uji coba terlebih dahulu dengan menggunakan white box testing.

\section{F. Evaluasi Sistem}

Setelah dilakukan uji coba sistem, kemudian dilakukan tahap evaluasi, apakah sistem telah memenuhi kebutuhan pengguna atau tidak. Jika sudah memenuhi maka kembali ketahap d dan e.

\section{G. Penggunaan Sistem}

Tahap terakhir dari model prototyping adalah penggunaan sistem. Program aplikasi website ini telah diuji dan diterima oleh komunitas pakar tanaman adenium dengan baik (tergantung pada komunitas pakar tanaman adenium ini akan menggunakan hasil penelitian ini atau tidak).
HASIL DAN PEMBAHASAN

\section{Algoritma Sistem Pakar}

Adapun algoritma dari sistem pakar ini adalah:

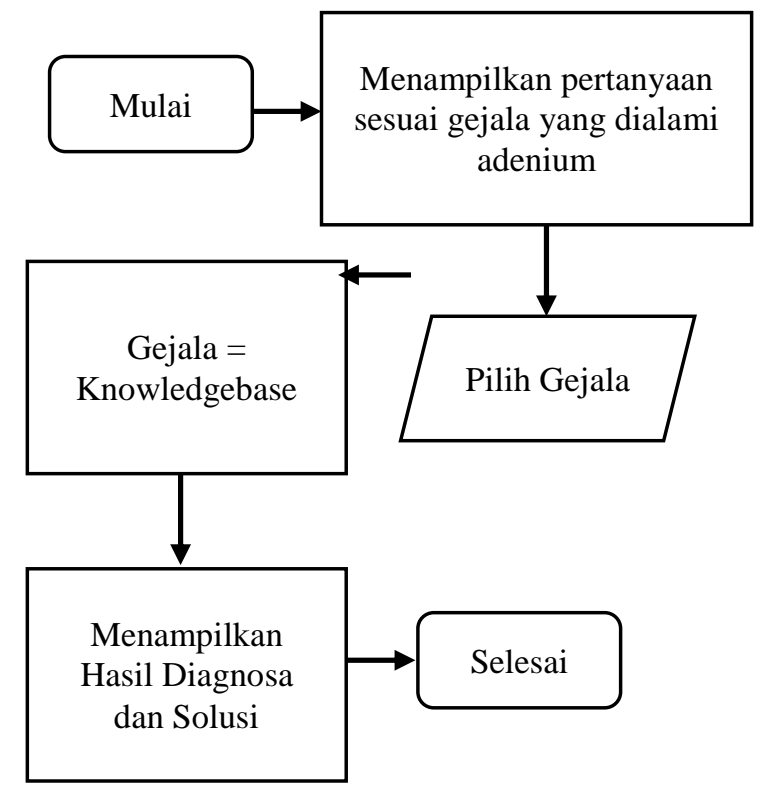

Gambar 1. Algoritma Sistem Pakar

\section{Basis Pengetahuan (Knowledge Base) Tabel Pakar}

Berikut adalah Basis Pengetahuan dari tabel pakar diagnosa penyakit tanaman adenium:

Tabel 1. Knowledge Base Penyakit Adenium

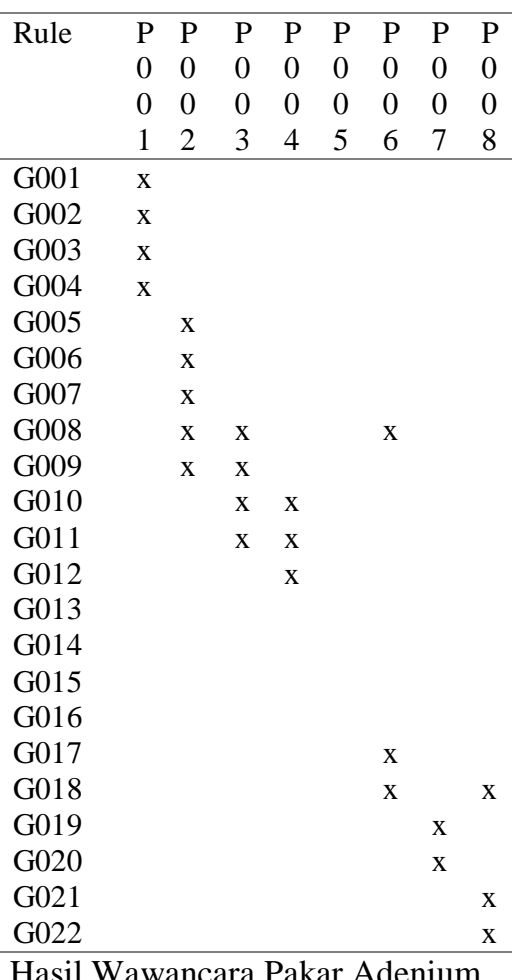




\section{Rule-Rule Sistem Pakar}

Berikut adalah rule dari sistem pakar mendiagnosa penyakit tanaman adenium:

\section{RULE 1 :}

Jika biji polong kempis

dan biji polong gugur

dan biji polong menghitam lalu busuk

dan biji polong keriput

maka adenium terserang hama kepik

\section{RULE 2 :}

Jika ada noda merah dipermukaan daun

dan daun pucat

dan daun layu

dan daun rontok

dan kuncup bunga rontok

maka adenium terserang hama tungau

\section{RULE 3 :}

Jika ada kuncup bunga bengkok

dan kuncup bunga rontok

dan bentuk bunga tidak normal

dan daun rontok

maka adenium terserang hama Thrips

RULE 4 :

Jika ada bercak coklat dipermukaan daun dan bunga gagal mekar lalu mengering dan bentuk bunga tidak normal maka adenium terserang hama fungus

\section{RULE 5 :}

Jika ada warna putih seperti tepung di seluruh bagian tanaman

dan pertumbuhan tanaman terhambat dan ada bintik hitam dipermukaan daun maka adenium terserang hama kutu putih

\section{RULE 6 :}

Jika ada bintik coklat di daun

dan daun menguning

dan daun rontok

maka adenium terserang phomopsis

\section{RULE 7 :}

Jika batang berubah warna menjadi coklat atau hitam

dan mengeluarkan bau tidak sedap

maka adenium terserang busuk batang

\section{RULE 8 :}

Jika batang menjadi lunak dan kulit batang mengkerut dan daun menguning dan daun rontok maka adenium terserang busuk akar
3. Pohon Keputusan

\section{Gejala Yang Ditimbulkan Oleh Tanaman Adenium :}

G001 : Biji polong kempis

G002 : Biji polong gugur

G003 : Biji polong menghitam lalu busuk

G004 : Kulit biji keriput

G005 :Terdapat noda merah dipermukaan daun

G006 :Daun Pucat

G007 : Daun Layu

G008 : Daun Rontok

G009 : Kuncup bunga rontok

G010 : Kuncup bunga membengkok

G011 : Bentuk bunga tidak normal

G012: Terdapat bercak cokelat pada kuncup bunga

G013 : Bunga gagal mekar lalu mengering

G014 : Terdapat warna putih seperti tepung diseluruh bagian tanaman

G015 : Pertumbuhan tanaman terhambat

G016 :Terdapat bintik hitam dipermukaan daun

G017 : Terdapat bintik cokelat dipermukaan daun

G018 : Daun menguning

G019:Batang berubah warna menjadi cokelat atau hitam

G020 : Mengeluarkan bau tidak sedap

G021 : Batang menjadi lunak

G022 : Kulit batang mengkeriput

\section{Hama dan Penyakit Tanaman Adenium:}

P001 : Hama Kepik

P002 : Hama Tungau

P003 : Hama Thrips

P004 : Hama Fungus Gnats

P005 : Hama Kutu Putih

P006 : Phomopsi

P007 : Busuk batang

P008 : Busuk Akar

Dibawah ini merupakan pohon keputusan dari sistem pakar mendiagnosa penyakit adenium: 


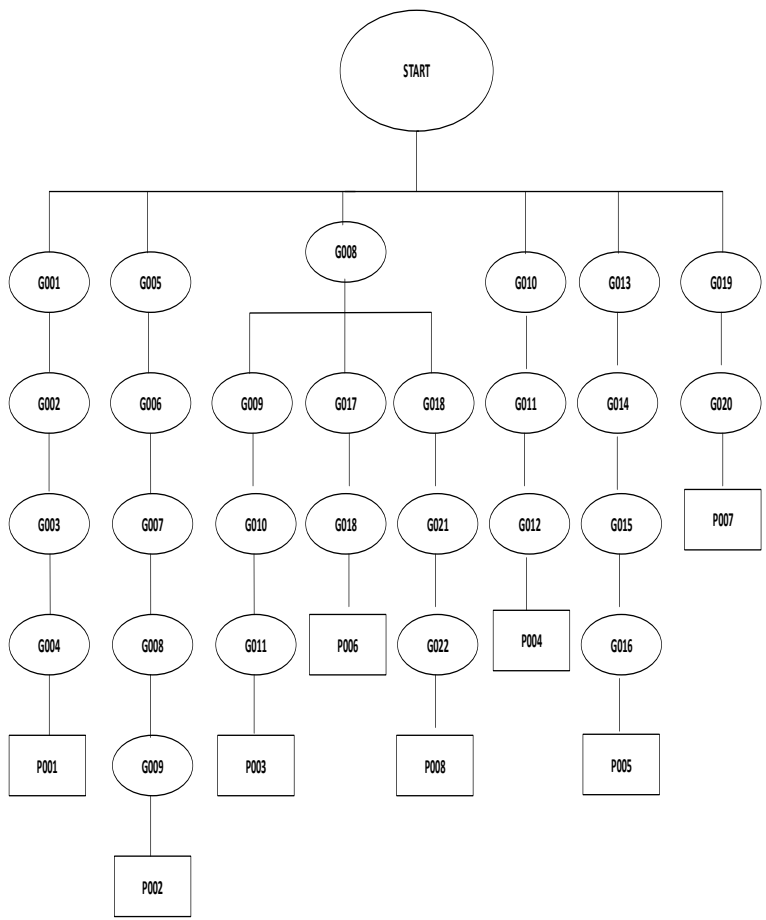

Sumber: Data Penelitian

Gambar 2. Pohon Keputusan

4. Usecase Diagram

\section{Usecase Diagram Halaman Administrator System}

Berikut adalah usecase diagram untuk halaman administrator system:

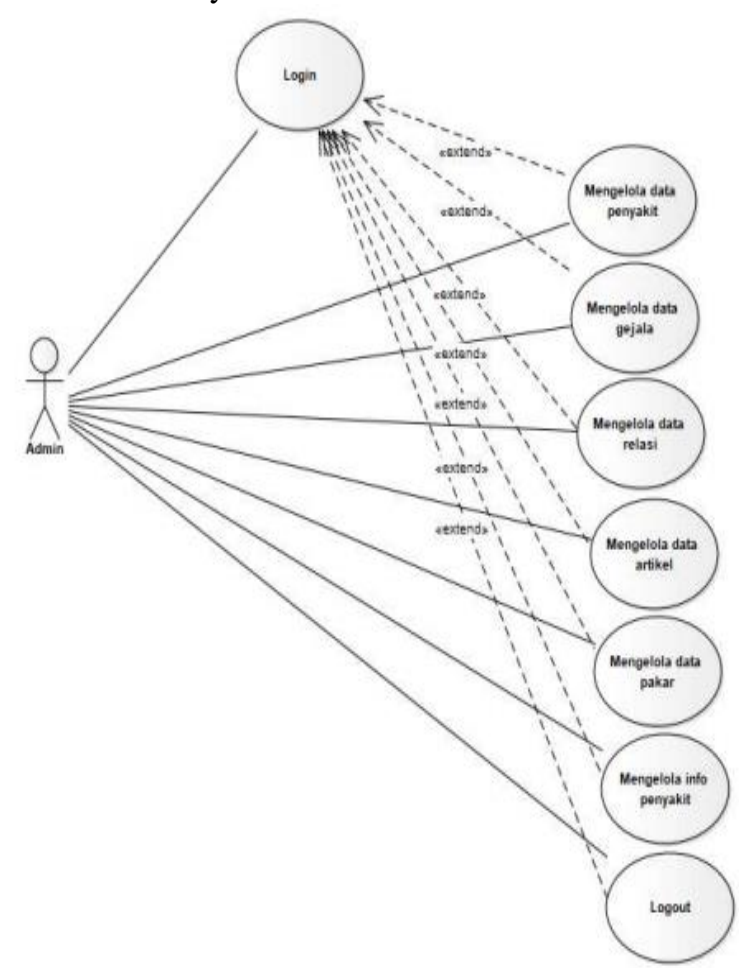

Gambar 3. Usecase Halaman Administrator System

\section{Usecase Diagram Halaman Pakar}

Berikut adalah usecase diagram untuk halaman pakar:

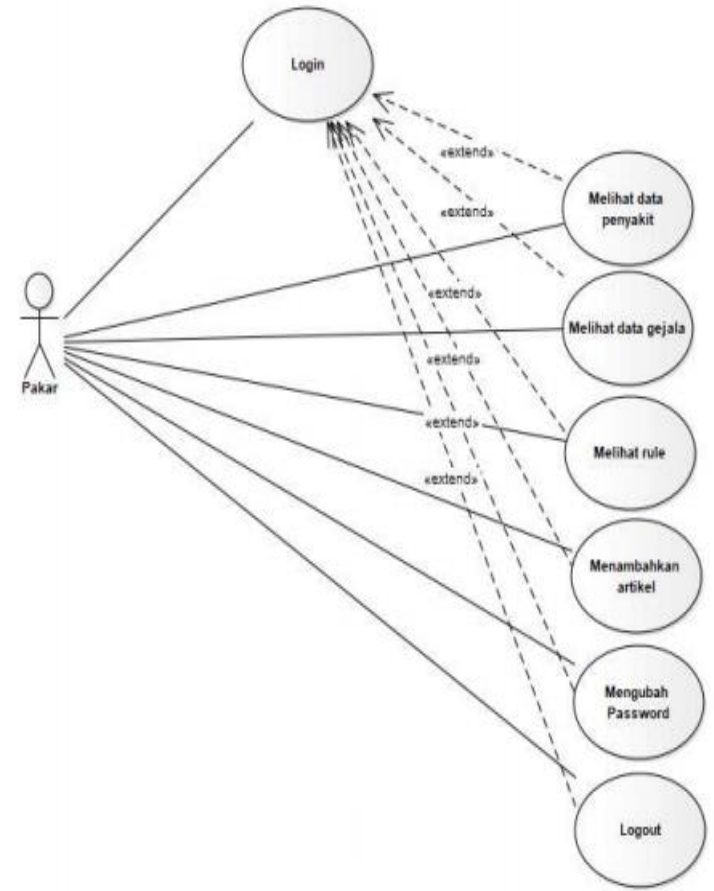

Gambar 4. Usecase Diagram Halaman Pakar 4. Activity Diagram

Berikut adalah activity diagram untuk halaman administrator system:

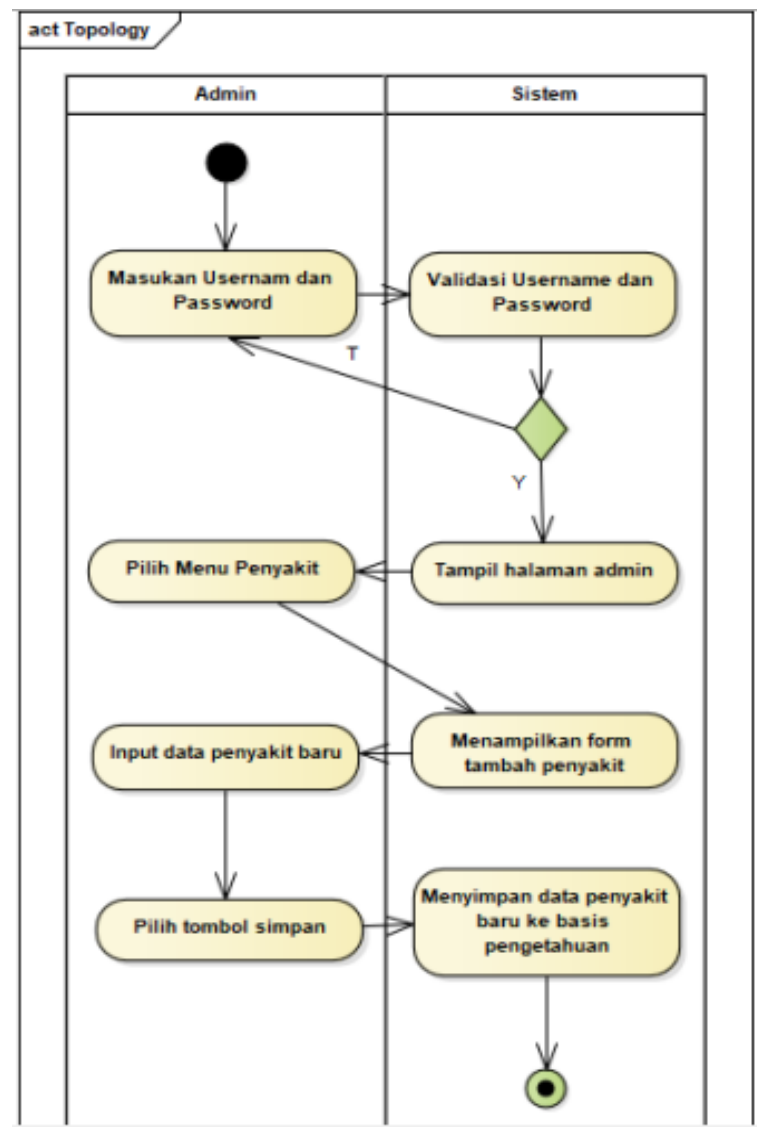

Gambar 5. Activity Diagram Halaman Administrator Sysem 
5. Deployment Diagram Berikut adalah gambar deployment diagram:

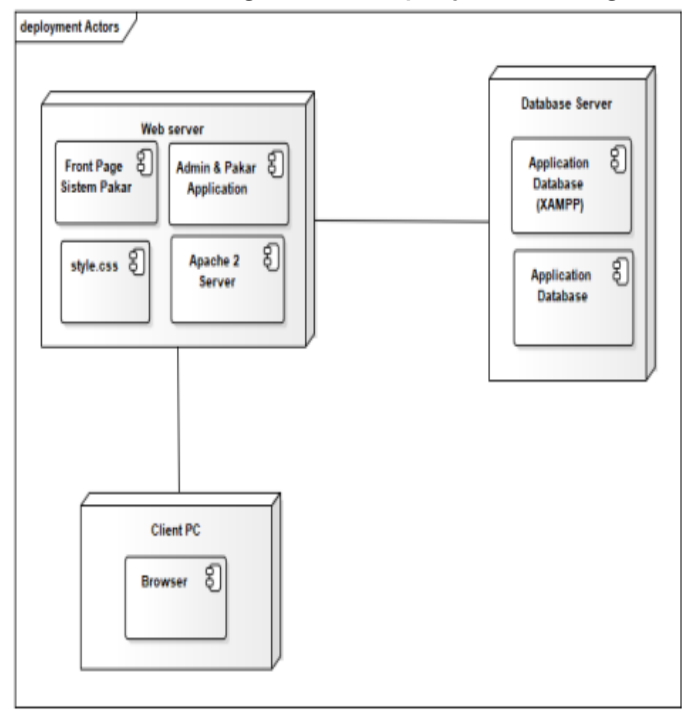

Gambar 6. Deployment Diagram

\section{Component Diagram}

Berikut adalah gambar component diagram

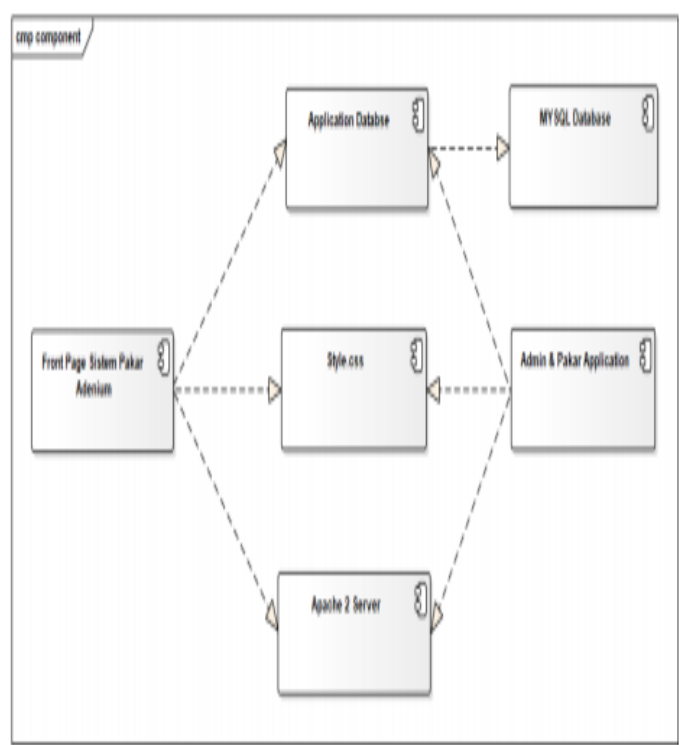

Gambar 7. Component Diagram

\section{ERD (Entity Relationship Diagram)}

Dibawah ini merupakan entity relationship diagram dari sistem pakar mendiagnosa penyakit adenium:

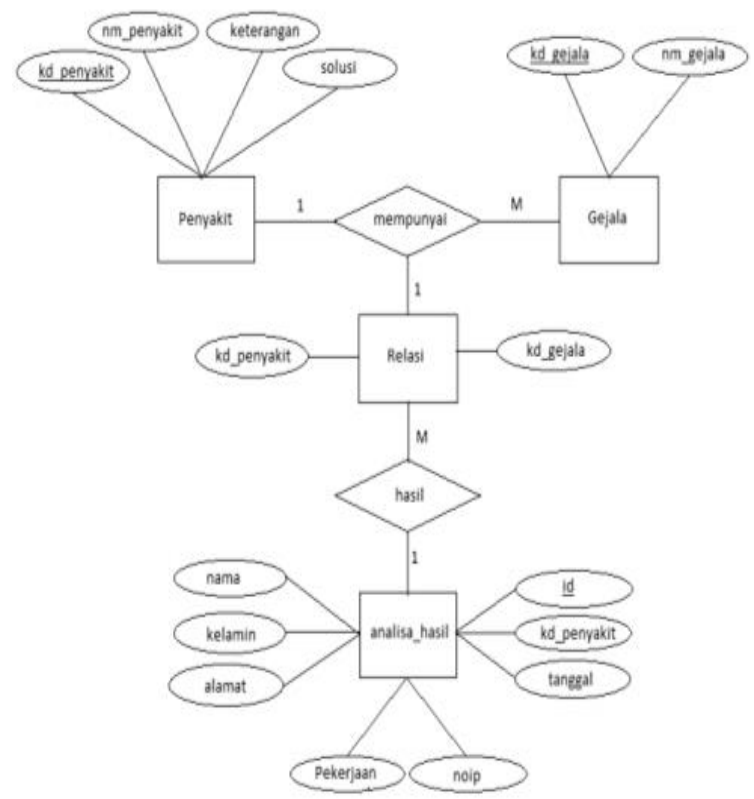

Gambar 8. ERD Sistem Pakar Mendiagnosa Penyakit Adenium

\section{LRS (Logical Relationship Structure)}

Dibawah ini merupakan logical relationship structure dari sistem pakar mendiagnosa penyakit adenium:

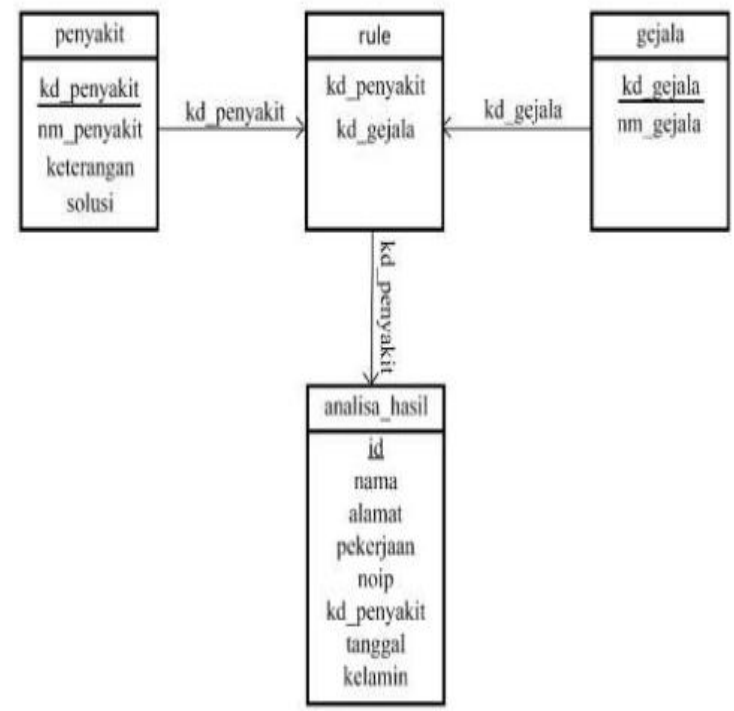

Gambar 9. LRS Sistem Pakar Mendiagnosa Penyakit Adenium

8. User Interface

Tampilan Pengunjung

Berikut adalah tampilan dari halaman pengunjung: 


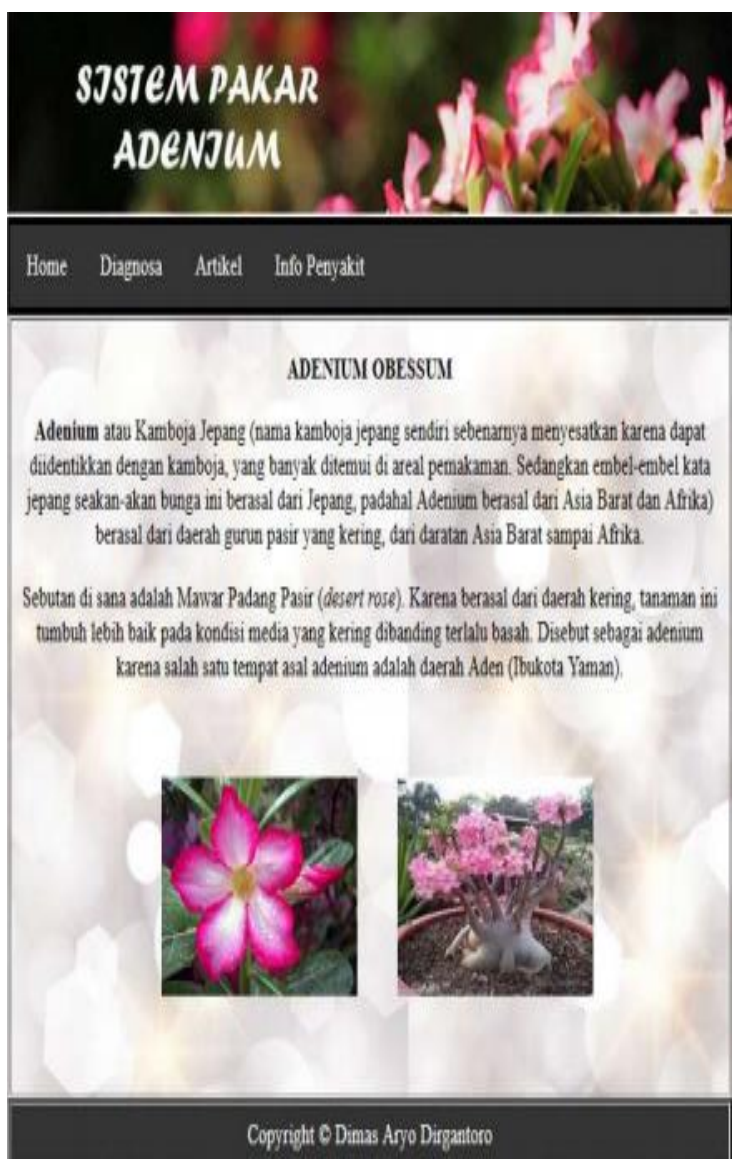

Gambar 10. Tampilan Pengunjung

Tampilan Menu Diagnosa

Berikut adalah tampilan dari halaman diagnosa:

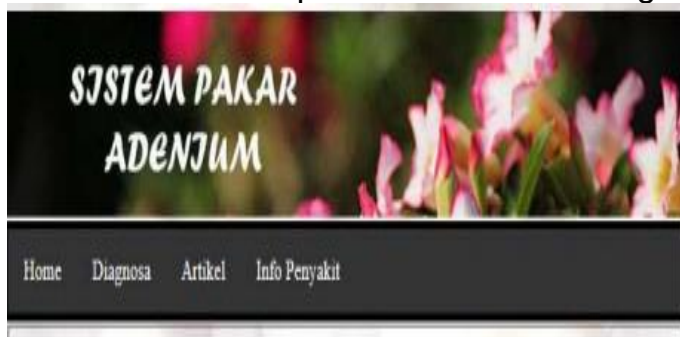

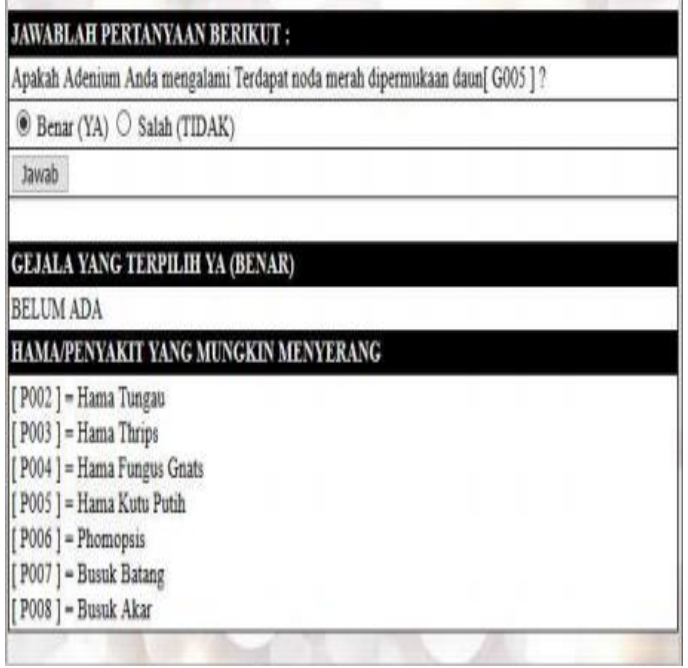

Gambar 11. Halaman Diagnosa
Tampilan Menu Hasil

Berikut adalah tampilan dari halaman Hasil diagnosa:

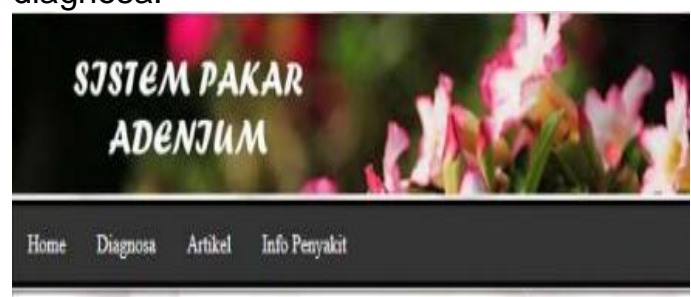

\begin{tabular}{|c|c|}
\hline \multicolumn{2}{|c|}{$\begin{array}{l}\text { HASIL ANALISA PENYAKTT ADENTIM } \\
\end{array}$} \\
\hline \multicolumn{2}{|c|}{ DATA PASIEN: } \\
\hline Nama & dimas \\
\hline Kelamin & Pria \\
\hline Alamat & Tangerang \\
\hline Pekejjan & Mahasiswa \\
\hline \multicolumn{2}{|c|}{ HASIL ANALISA IERAKHIR: } \\
\hline $\begin{array}{l}\text { Nama } \\
\text { Penyakit }\end{array}$ & P002 Hama Tungau \\
\hline Gejala & $\begin{array}{l}\text { 1. Kuncup bunga foatok } \\
\text { 2. Daua roatok } \\
\text { 3. Daua layu } \\
\text { 4. Daun Pucat } \\
\text { 5. Terdapat noda merah dipermukann daun }\end{array}$ \\
\hline Keterangan & 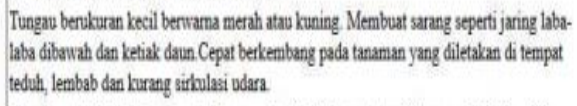 \\
\hline Solusi & $\begin{array}{l}\text { Gunakan alarisida berbahan altif propargit, dikcofol, atau tetradifon seperti Omite } 570 \\
\text { EC.Setelah divemprot tanaman alan mengugurkan daun dan daun barv alan tumbuh }\end{array}$ \\
\hline
\end{tabular}

\section{Tampilan Menu Penyakit}

Berikut adalah tampilan dari halaman Menu Penyakit:

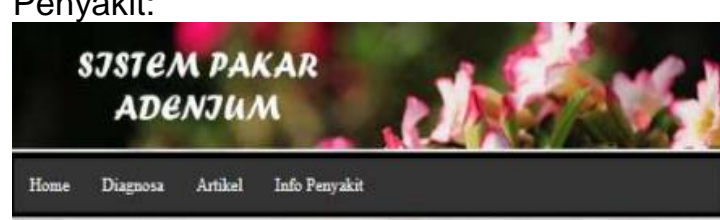

Hama Kepik Hama ini biasa merusak polong dan biji dengan cara menusuk kulit polong dan je

Hams Tuggas

Tungau beruhuran kecil berwama merah atau laning, Membuat sarang seperti jaring laba-laba dibawah dan ketiak daun. Cepat beikembang pada tanman yang diletakan di tempat teduh, lembab dan kurang sirku. Baca Selenzlannara

\section{Hama Thrips}

Hama ini beruhuran kecil seperti kutu, benwama hitam das lincah. Lana hama ini bersarang pada kuncup tunga dan daun Baca Selenghasura

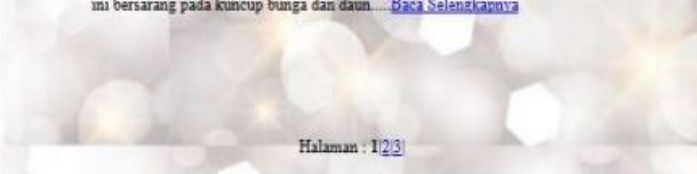

Gambar 13. Halaman Menu Penyakit 


\section{KESIMPULAN}

Berdasarkan pemaparan dari pembahasan diatas, perancangan aplikasi sistem pakar berbasis website ini dapat disimpulkan berbagai macam manfaat yang diperoleh diantaranya:

1. Adanya sistem pakar mengenai penyakit tanaman adenium berbasis website ini, dapat membantu para pemilik dan penghobi tanaman adenium dalam mengatasi penyakit yang menyerang tanaman tersebut dengan mendeteksi gejalagejala yang ditimbulkan, dan

2. Adanya sistem pakar ini, dapat dijadikan alat dokumentasi penyimpanan pengetahuanpengetahuan yang dimiliki oleh para pakar agar dapat bermanfaat bagi orang banyak (khususnya para pecinta dan penghobi tanaman adenium).

Dari kesimpulan tersebut, sistem pakar berbasis web ini masih terdapat beberapa kekurangan yaitu diperlukannya penambahan informasi tentang penyakit adenium agar dapat mengenali lebih banyak penyakit serta gejalanya yang ditimbulkannya, diharapkan bagi para pembaca yang tertarik untuk melakukan penelitian yang serupa dapat melakukan pengembangan dari website ini dan dapat menggunakan metode sistem pakar yang laiinya agar lebih menambah wawasan kita serta dapat menambah keakuratan dari data yang dihasilkan.

\section{REFERENSI}

Kusrini. (2008). Aplikasi Sistem Pakar Menentukan Faktor Kepastian Pengguna Dengan Metode Kuantifikasi Pertanyaan. Yogyakarta: CV. Andi Offset. Retrieved from

https://books.google.co.id/books?id=eVLp Mloxq8|C\&hl=id\&source=gbs_similarbooks

Madcoms. (2009). Menguasai XHTML, CSS, PHP \&amp; MySQL Melalui Dreamweaver Edisi 1 (1st ed.). Yogyakarta: Andi. Retrieved from http://openlibrary.telkomuniversity.ac.id/pu staka/19181/menguasai-xhtml-css-phpmysql-melalui-dreamweaver-edisi-1.html.

Merlina, N. dan R. H. (2012). Perancangan Sistem Pakar, Studi Kasus: Sistem Pakar Kenaikan Jabatan. Bogor: Ghalia Indonesia. Retrieved from http://digilib.batan.go.id/ppin/libppiksn/inde x.php?p=show_detail\&id=17611.

Raharjo, Budi. (2015). Belajar Otodidak MYSQL (Teknik Pembuatan dan Pengelolaan Database). Bandung: Informatika. Retrieved from http://openlibrary.telkomuniversity.ac.id/pu staka/103159/belajar-otodidak-mysqlteknik-pembuatan-dan-pengelolaandatabase-.html.

Ramadhan, Arief. (2007). Student Excercise Series - Pemrograman Web Database dengan PHP \&amp; MySQL - Arief Ramadhan - Google Buku. Jakarta: Elex Media Komputindo. Retrieved from https://books.google.co.id/books/about/Stu dent_Excercise_Series_Pemrograman_W eb.html?id=6UVGDwAAQBAJ\&redir_esc= y.

Rosa AS, M. Shalahudin. (2014). Open Library Rekayasa Perangkat Lunak: Terstruktur dan berorientasi objek. Bandung: Informatika. Retrieved from http://openlibrary.telkomuniversity.ac.id/pu staka/30286/rekayasa-perangkat-lunakterstruktur-dan-berorientasi-objek.html.

Sidik, Betha. (2014). Pemrograman Web dengan PHP: Edisi Revisi Kedua. Bandung: Informatika. Retrieved from http://openlibrary.telkomuniversity.ac.id/pu staka/98620/pemrograman-web-denganphp-edisi-revisi-kedua.html.

Tanshidiq, A.M.R, Hartanto A.D dan Donni Prabowo. (2017). Penerapan Metode Forward Chaining Pada Aplikasi Sistem Pakar Diagnosa Penyakit Pada Tanaman Bunga Kamboja (Adenium). IImiah DASI, 18, 1411-3201.

Yunizar, Z. (2015). Penerapan Sistem Pakar Dalam Mendiagnosa Penyakit Pada Tanaman Adenium ( Kamboja Jepang ). Penerapan Sistem Pakar Dalam Mendiagnosa Penyakit Pada Tanaman Adenium (Kamboja Jepang), 15(16), 95101. 


\section{PROFIL PENULIS}

Syahriani, memperoleh
gelar Sarjana Komputer
(S.Kom), jurusan Sistem
Informasi STMIK Nusa
Mandiri Jakarta, lulus tahun
2010, Memperoleh gelar
Magister r Komputer
(M.Kom), Program Pasca
Sarjana Magister Ilmu
Komputer STMIK Nusa
Mandiri Jakarta, lulus
tahun 2015. Saat ini menjadi
Dosen di STMIK Nusa
Mandiri Jakarta.

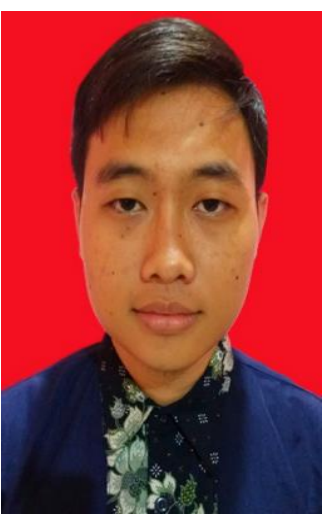

Dimas Aryo D,memperoleh gelar Sarjana Komputer (S.Kom) , jurusan Sistem Informasi STMIK Nusa Mandiri Jakarta, lulus tahun 2018. 